\title{
The economics-engineering nexus: response to the commentaries
}

\author{
Sergio Mariotti ${ }^{1}$
}

Received: 2 October 2021 / Revised: 31 October 2021 / Accepted: 3 November 2021 /

Published online: 17 November 2021

(c) The Author(s) under exclusive licence to Associazione Amici di Economia e Politica Industriale 2021

\begin{abstract}
This paper contributes to the debate on the relationship between economics and engineering that was opened in a previous article by the author and the comments made on the subject by other scholars, all published in the 4/2021 Issue of the Journal. It discusses the knowledge advancement and problem-solving opportunities offered by the interaction and cross-fertilization that occurs between the two disciplines. It claims that the distance between the epistemology and mentality of fundamental branches of economics and engineering is narrowing, thereby allowing a fruitful knowledge collaboration. An alliance between independent peers is the best form of governance to exploit the potentialities inherent to the relationship, as an alternative to both "economic imperialism" and "reverse imperialism". Relatedly, the paper delves into the role of economic complexity and artificial intelligence in pushing this paradigm shift of the economics-engineering nexus, and it re-discusses the meaning and content of transdisciplinarity in the context of such an alliance. Finally, the paper expresses the hope that these topics will become a matter of debate in a widespread community of scholars.
\end{abstract}

Keywords Artificial intelligence · Complexity · Economics-engineering nexus · Epistemology $\cdot$ Transdisciplinarity $\cdot$ Unification of knowledge

JEL Classification A12 - A20 - B50 - N01

Sergio Mariotti

sergio.mariotti@polimi.it

1 Department of Management, Economics and Industrial Engineering, Politecnico di Milano, Milan, Italy 


\section{Premise}

It was a great pleasure to read the insightful comments on my paper by Richard Adelstein, Silvano Cincotti, César García-Díaz, Adam Fforde, Robert Hébert, Cyrille Rigolot and Peter Swann. I am grateful to them for their kindness, but above all for the care with which they examined, criticized and developed what I tried to do by investigating the history and perspective of the intriguing relationships between economics and engineering (Mariotti, 2021). These colleagues discussed a wide range of topics and presented interesting and inspiring ideas and suggestions. I will mainly focus on the more controversial issues rather than on points of agreement. However, before responding, to make readers more informed on the subject and more familiar with the related issues, I will present a brief summary of my previous article. Furthermore, in my next response I will exploit the proposals and suggestions articulated in the comments, which either correct or enrich my approach and policy considerations. I hope my response better elucidates the "quixotic quest" which I have embarked on (to use an expression of Hébert's, 2021, p. 613).

\section{Forging a new alliance between economics and engineering: a brief summary}

In Mariotti (2021), I investigated the historical evolution of the economics-engineering nexus since the contribution of Jules Dupuit and the French school of econo-engineers to the foundation of neoclassical economics in the nineteenth century. I identified three paradigms-economics "forland/as" engineeringwhose dynamics and interweaving allow us to understand how the two disciplines have become related to each other over time. In a nutshell: (1) economics for engineering can be considered as an ancillary subset of economic concepts, methods and tools at the service of project evaluation and decision making in the engineering-technological field; (2) economics as engineering corresponds to the adoption, by economics, of the engineering epistemology for market design and problem solving, through commonalities of language, methodology, and research organization; (3) economics and engineering suggests the meeting between economics and engineering as peers, i.e., respecting the disciplinary singularities and the different cultures of each, but in a context of cross-fertilization and interdisciplinarity.

After discussing the specific dimensions of the three paradigms, I concluded that the modes of interaction described by each of these paradigms are insufficient to address the challenges of complexity in contemporary and future society, which are increasingly influenced by artificial intelligence (AI) technologies. On the one hand, although prominent economists have called for greater heterodoxy in economic theory and modeling, mainstream economics has been extremely reluctant to accept the epistemological implications of complexity, and has instead been adopting a reductionist approach, so as to borrow some tools without changing 
their foundations. On the other hand, the top engineering schools, equating economic education with the activities of typical business schools, have trained a generation of engineers who are inclined to open the black box of economic complexity only to find tools that help them formally solve the problems associated with the intricacies of their discipline, but who do not take into account much of the different reality of the organizing, managing and leading social and economic activities in practice and who fail to serve the public interest. In this context, the "meeting of minds" between mainstream economists and unreflective engineers seems unable to generate a new, shared and coherent epistemology of complexity.

In relation to this state-of-the-art, the paper called for a new alliance between economics and engineering driven by a transdisciplinary-oriented change in the epistemology and methods of the two disciplines and in their way of being and interacting. In such a context, the reference to transdisciplinarity was intended to draw attention to the search for apparent and hidden connections between the two disciplines, and to the training of a generation of researchers and scientists as integral thinkers who are mindful of the need for plurality and for synergizing theories and knowledge across the edges of traditional disciplines. The examples of mechatronics, biotechnology, and the same AI as fields of transdisciplinarity served to make the point clear.

Coming now to the main criticisms of colleagues, and therefore to the next contents of the present article, I will first discuss the argument that the epistemological nature of economics and engineering and the mindset involved are so different that an alliance would be counterproductive and, if attempted, it would generate tension and risks of domination of one discipline over the other, with pernicious effects on the dominated discipline or on both (see, in particular, the comments by Adelstein, 2021; FForde, 2021; Hébert, 2021). Second, I will delve into the previous insufficiently specified roles of economic complexity and AI in demanding a change in the economic-engineering nexus (see the comments by Cincotti, 2021; Fforde, 2021; García-Díaz, 2021). Third, I will examine the alternative ways by which the two disciplines can interact, referring to the "economics imperialism versus reverse imperialism" debate and proposing the alliance as the best governance (see the comments by Adelstein, 2021; Hébert, 2021; Swann, 2021). Finally, I will re-discuss the meaning and content of transdisciplinarity in the context of the alliance between economics and engineering (see the comments by García-Díaz, 2021; Rigolot, 2021).

\section{Is the epistemological gulf between economics and engineering really that wide?}

In this section, ${ }^{1}$ I will examine the epistemological divergences, but also convergences, between economics and engineering. In the commentaries on my paper, the former is alternatively thought of as a genuine science (Adelstein, 2021), as a

\footnotetext{
${ }^{1}$ Hereafter in the text, all the sentences quoted from the comments on my previous article start on a new indented line.
} 
social science (Hébert, 2021; Swann, 2021), or perhaps as a pseudo-science (Fforde, 2021). My argument is based on the distinction between pure sciences and engineering, and on the tripartite division of economics into positive, normative and art (Keynes, 1890). This allows me to discuss the interrelationships between the different disciplinary branches and to conclude that the gulf between economics and engineering is not as wide as it is commonly thought to be by many economists, by being bridged by the common "willing-orientation" of engineering and applied economics (i.e., the "art" of economics). This epistemological commonality allows us to think of an effective synergy and joint problem solving by the two disciplines in the relevant application fields (see Sect. 6).

\subsection{Scientists, engineers, and billiard players}

Quoting Edward Laezer, García-Díaz (2021, p. 602) reminds us of the widespread opinion among economists that:

«[e]conomics is not only a social science, it is a genuine science».

Adelstein adds that:

«[s]cience is not engineering. For all the human imperfection that pervades the scientific enterprise, most scientists are trained to consider their work and describe it to others as a search for objective truth that is assumed to be "out there," waiting to be discovered» (Adelstein, 2021, p. 574). Coherently, «[e] conomics, ideally a positive science pursuing knowledge "for its own sake", is distinguished from engineering, an intrinsically purposive attempt to control nature or people to serve human interests» (Adelstein, 2021, p. 573). However, «economists have largely effaced the distinction between science and engineering and made it much harder for themselves and others to perceive and evaluate the purposes to which their theories are put [...][Thus,] [b]y building the telos of engineering into the DNA of his new social science, Mariotti's melding of the two disciplines would only exacerbate this problem, placing a normative, problem-solving ethos at the core of what ought to be an inquisitive positive science» (Adelstein, 2021, p. 576).

When considering engineering, it is possible to say, yes, it differs from science. I find the explanation of Jon Alan Schmidt, a structural engineer at Burns $\&$ McDonnell, and also a philosopher of engineering, one of the best ones: «[s] cience is widely perceived as an especially systematic approach to knowing; engineering could be conceived as an especially systematic approach to willing» (Schmidt, 2013, p. 103). Specifically, scientists observe natural phenomena, propose hypotheses to explain them, and conduct experiments to test their 
theories. Although "will" is implicitly involved (the goal being additional objective knowledge), intellect is of primary importance. Engineers use heuristics to cause the best change with the available resources in a poorly understood situation. Although intellect is implicitly involved, "will" is of primary importance, the goal being a "subjective outcome", for which knowledge serves as a necessary but insufficient means.

The proposed framework also recognizes the mutual interactions between knowing and willing, and thus between science and engineering. "Attentive experience, intelligent understanding, and reasonable judgment lead people to adopt beliefs about how the world was in the past and is now; considerate deliberation and responsible decision lead people to make choices about how the world will be in the future» (Schmidt, 2013, p. 107). The Nobel laureate in Economics Herbert Simon, with reference to AI (of which he is considered one of the fathers) describes the many ways by which AI, defined as "empirical science", interacts with engineering. His conclusions are: «[w]e see that, far from striving to separate science from engineering, we need not distinguish them at all [...] [a]lthough there is also a large element of chance in human design processes, chance is moderated by heuristics that use prior knowledge, what is already known about the systems of interest, to generate and combine elements in a very selective way, greatly increasing the odds that the product will be functional. While the scientist is interested specifically in creating new knowledge, the engineer is interested also in creating systems that achieve desired goals. Apart from this difference in motives, there is no need to distinguish between computer scientists and computer engineers, or AI scientists and engineers. We can stop debating whether AI is science or engineering; it is both» (Simon, 1995, p. 100).

Thus, the boundaries between science and engineering can only be defined in an abstract manner, but their close interaction is of paramount importance for the progress of both. To clarify this point, I would like to consider Milton Friedman's billiard metaphor, which is particularly familiar to economists. Friedman used it to support his methodological instrumentalism, founded on the irrelevance of hypotheses, on the judgment of the validity of theories by reason of their predictive power, and on the functioning of the "natural selection" process in shaping the economy. In this subsection, I refer to the same metaphor to elucidate science-engineering relationships, but I will not disdain to draw some insights from it for economic science.

Friedman's example is «[c]onsider the problem of predicting the shots made by an expert billiard player. It seems not at all unreasonable that excellent predictions would be yielded by the hypothesis that the billiard player made his shots as if he knew the complicated mathematical formulas that would give the optimum directions of travel, could estimate accurately by eye the angles, etc., describing the location of the balls, could make lightning calculations from the formulas, and could then make the balls travel in the direction indicated by the formulas. Our confidence in this hypothesis is not based on the belief that billiard players, even expert ones, can or do go through the process described; it derives rather from the belief that, unless in some way or other they were capable of reaching essentially the same result, they would not in fact be expert billiard players» (Friedman, 1953, p. 157-158). 
In this example, we are attempting to model the behavior of experienced billiard players. The model solves the optimization for force and direction, given the placement of balls on the table. It is not that the experienced billiard player actually solves this optimization problem with each and every shot; rather, the billiard player acts "as if" their behavior was determined by solving a mathematical program.

Now let us suppose Friedman witnesses a pool tournament attended by the strongest players in the world, and that he brings a state-of-the-art optimization model with him. His logical expectation is that the greatest number of players will throw balls according to the model's prescription. Surprisingly, he would observe that a significant portion of players do not behave in this way. Why?

Engineering helps us to understand. To paraphrase Friedman's previous words, it would seem "not at all unreasonable" that a robot that incorporates all the needed mathematics and environmental physics will easily win a game when the opponents are human. In fact, the challenge of creating a robot accurate enough to compete and win against top professional players has always been a strong motivator for the robotics field. Many projects have been developed since the mid-1990s, and engineers are agonizing over finding the right solution to the problem (Landry et al., 2013). Engineers quickly discovered that «[t]he game of billiards is a game of skill, tactics, and ingenuity» (Landry et al., 2013, p. 325). The outcome of the game depends not only on the capacity of the players to approximate the laws of physics, but primarily on the attack or defense strategies that are adopted, ${ }^{2}$ the perceptions of their own limits and external risks, the ability to interpret the opponent's behavior and psychology, in order to counteract in an adequate manner.

Finding the optimal technology requires much more than the basic laws of physics and complex mathematical equations, as Friedman assumes in his example. In a work with the revealing title "Robotic billiards: understanding humans in order to counter them", Nierhoff et al. (2016) argued that: "[t]o succeed against a human in a competitive scenario, a robot must anticipate the human behavior and include it in its own planning framework. Then it can predict the next human move and counter it accordingly, thus not only achieving overall better performance but also systematically exploiting the opponent's weak spots. Pool is used as a representative scenario to derive a model-based planning and control framework where not only the physics of the environment but also a model of the opponent is considered. By representing the game of pool as a Markov decision process and incorporating a model of the human decision-making based on studies, an optimized policy is derived. This enables the robot to include the opponent's typical game style into its tactical considerations when planning a stroke» (Nierhoff et al., 2016, p. 1889). «The presented approach based on a Markov decision process (MDP) is able to take both hardware limitations and a detailed model of the human decision-making process into

\footnotetext{
${ }^{2}$ A billiard defense strategy consists in leaving a bad shot for the rival. That is, the player disregards the main goal of billiards (putting balls into holes), to force the opponent to play badly and to make it easier to put the balls in later. Even if the players decide to attack, if the shot is very complicated, they have to consider what the best way is to execute it so that, in the case of failure, the opponent then makes a bad shot.
} 
account. Thus the robot can predict the human's actions and adapt to them by deriving an optimized policy. Due to the competitive nature of the game, the approach resembles a expectiminimax tree» (Nierhoff et al., 2016, p. 1890). «Differing from a rationally acting robot who will pocket the ball with the highest action-value function, unknown human likings or limitations may favor a different stroke» (Nierhoff et al., 2016, p. 1893). Thus, in most situations, it is important that the robot predicts human decisions to react appropriately. To do this, the robot must be an anthropomorphic robot equipped with a probabilistic search algorithm. This way, «a robot facing a human in a competitive task can improve its performance through extensive planning and precise representation of the opponent's behavior. This allows the robot to adapt to human-specific decision-making and the opponent's individual motor skill while overcoming its own kinematic constraints» (Nierhoff et al., 2016, p. 1898).

Astonishingly, the robot, equipped with the best algorithms and optimization programs, must behave as if it were a human to win. In this sense, in the opposite way of Friedman's statement. Accordingly, scientists (computer scientists, neuroscientists, mathematicians, physicists, etc.) and engineers (industrial engineers, mechatronics engineers, operational researchers, etc.) joined together to enable robotic-based systems to interact with humans in the real world. Such a bidirectional interaction is quite evident: from engineering to science, by suggesting the failures of scientific modeling and the need to develop new knowledge along selected directions, and from science to engineering, by making new conceptual tools for robotic design available. Apparently, there are no epistemological conflicts, and only virtuous circles are at work.

What can engineers suggest to scientists (and to economists as scientists) by leveraging on the experience of billiard robotics? First, playing billiards does not boil down to invariant regularities related to the physical environment, as the causal link between the variables is human action. Second, the outcome of the game does not respond to a logic of stable factors, but to a logic of trees and open-ended results.

On the other hand, according to the "will" imperative, engineers cannot simply wait for a fertile interaction with scientists to produce the perfect robot. Indeed, they have to offer the second-best solution with the available resources. It is clear how the engineer who has the player as a client will try to help him with his ingenuity, heuristics, and science-based knowledge. And that is exactly what happens.

Shane Wighton is a mechanical and computer science engineer, best known for his engineering-focused YouTube channel, Stuff Made Here. A recent piece of news has appeared on the Internet entitled "Going straight to the hole is no longer a problem". We read that Shane «has designed and built a $100 \%$ foolproof robotic pool cue [...] Shane used two basic components: a video camera mounted on the table and a system of 6 mechanical arms installed on the tip of a common pool cue. The camera analyzes the position of the balls and, thanks to a projector, suggests to the player the best trajectory and angle from which to hit the ball. At this point, the system of mechanical arms - controlled by a Stewart platform-calibrates the power of the shot and allows the ball to be hit with the right accuracy every time. The result is spectacular: the robotic cue has 100\% infallibility» (https://www.thepatent.news/ 2021/04/18/robotic-pool-clue-foolproof-video/). 
We have learned that the pool game is more than just putting a ball into a hole accurately, but Shane's client has a huge advantage. In this regard, if all players equipped themselves with the same robotic cue, billiards would lose some of its charm.

\subsection{Economic scientists, applied economists, and social billiards}

Now let us talk about the game of "social billiards", in which a policy maker must strive to ensure the economic health and growth of the population (maybe his voters), by using art and heuristics. Surely an economic scientist will study the system and look for regularities that allow him to predict the economic trend and the behavior of an expert policy-maker. But will there be a similar figure to the engineer who will help the policy maker in his decisions, perhaps giving him something like a "social cue"? The answer is yes, and this figure is "the applied economist", where the term "applied" means the application of theoretical conclusions to guide policy or action. However, the profession of the applied economist has not been clearly defined. At times, he has been mistaken for or made to coincide with the economic scientist (who is also engaged in empirical work to test the validity of the theory), as shown by the analogies coined for the economist tout court as "a dentist, or a surgeon, or an engineer, or a plumber".

In order to clarify this matter, Su and Colander (2021) argue that economics is not a single entity, and each entity has separate goals, methods, and boundaries. Specifically, the boundary between economic science and applied economics should be recognized. The aforementioned authors evoke John Neville Keynes's (1890) threefold partition of economics into positive economics, normative economics, and art of economics. Accordingly, positive economics is defined as «a body of systematised knowledge concerning what is»; normative economics is understood as a «body of systematised knowledge relating to criteria of what ought to be, and therefore, concerned with the ideal as distinguished from the actual»; art of economics is described as a «system of rules for the attainment of a given end» (Keynes, 1890, p. 34; stress added), i.e., it is not about goals, but about how to achieve them (Keynes, 1890, p. 34; stress added).

As the history of economic thought teaches us, debates on the division of economics into a positive and normative branch, as well as the notion of economic value and the role of value judgements in economics, have never vanished among philosophers, historians, and economists (e.g., Blaug, 1992; Colander \& Su, 2015; Davis, 2005; Hands, 2012; Mirowski, 1990; Mongin, 2006). The distinction remains controversial, especially as regards the ambiguity that emerges when distinguishing between normative and the sometimes implicit and unconscious derivations of positive economists of "ought to be" from "is" (for a thorough discussion on the question, see the recent book by Ostapiuk, 2020, particularly pp. 27-32). However, this debate is not the focus of Su and Colander's work on this occasion ${ }^{3}$ and this is also true for myself. Rather, it is argued that the art of economics corresponds to the

$\overline{3}$ See Colander and $\mathrm{Su}$ (2015) for their position in the positive-normative debate. 
applied economics approach, according to which theories and methods are selected and applied to achieve an intended goal in the best way possible, given the available resources. In light of this, it is clear that applied economists share the "willing" approach of a genuine engineer, thus revealing an epistemological convergence.

Ultimately, economics includes both scientific economics and applied economics, and the boundaries of scientific economics should not be confused with the boundaries of economics. The very distinctive feature of applied economics is the application of theoretical conclusions, together with contributions from other noneconomic sciences to policy advice. «It follows that the conclusions reached by economics alone cannot provide policy prescription. Once the disciplines had separated, to reach a policy recommendation, a collaboration among disciplines became required» (Su \& Colander, 2021, p. 300). In the progress of their ideas, Su and Colander refuse Duflo's plumber analogy, on the grounds that it does not distinguish between scientific and applied economics, and propose the analogy between the applied economist and the "general contractor", who «has an overview of the entire project-she is in constant contact with engineers, plumbers, carpenters, architects, mechanical technicians, and she also knows, and works with, the customer of the policy integrating his values into the design of the policy» (Su \& Colander, 2021, p. 309). In their real life, economists may play multiple roles (acting as a scientist or as a general contractor). The point is that they need to match their methodologies to fit the role they are playing. And this makes the job of economists particularly difficult to execute and to understand from outside. Making sure that an implemented policy will work effectively to achieve goals is not the job of the economist-as-plumber, as in Duflo's discussion, but of the economist-as-general-contractor.

In this context, despite the criticism of Su and Colander, Duflo (2017, pp. 19-21) nevertheless contributed to making it clear what the relationships and the advantages are that are derived from applied economics for positive economics. For example, it is possible to evaluate the equilibrium effects of certain policy measures, test specific theories, discover unknown factors of influence, draw attention to new challenges and problems, and thus generate new economic insights in various ways. Depending on the outcome, this translates into added value that can be generalized or simply generate a positive welfare effect.

Looking again at Friedman's example, I found no information in Friedman's biographies to say whether he was a good billiard player or not. I guess not, even though he certainly frequented the billiard rooms of the Quadrangle Club. ${ }^{4}$ If he had been an experienced player, he would have reflected at length on both the appropriateness of the metaphor in support of the "as if" methodology, and on the consequences of his proclaimed irrelevance of assumption testing in the realm of positive economics. Indeed, the use of unrealistic assumptions can lead to an incorrect interpretation of reality, despite the alleged predictive power of the model (Leontief, 1971). The realism of substantive assumptions is critical, since it helps to ascertain the degree of

\footnotetext{
4 The historic membership club designed for the faculty, staff and community members of the University of Chicago.
} 
resemblance between the models and the target system (Ivarola, 2018). Thus, expert applied economists will not rely solely on the predictive capacity of theories with unrealistic assumptions, but will also adjust their policy design, making use of theories that are more verifiable and realistic.

\subsection{Economists, social planners, and the "engineering mentality"}

Hébert (2021) leads us to further refine our analysis, and to delve into the differences between economics as a "social science", on the one hand, and "pure" sciences and engineering, which he tends to mix with each other, on the other hand. He draws our attention to Hayek's writings on the economics-engineering nexus:

«Hayek claimed that the gestalt of economics is different from the gestalt of engineering; and this difference leads to pernicious social and political consequences. In making his case, Hayek delineated between the 'objective' nature of science and the 'subjective' nature of social studies. The object of science, he contends, is the study of phenomena independently of what people think about them; whereas the object of social studies is to understand all that people know and believe about themselves and their interrelationships to each other and to their external world; everything, in other words that determines human actions, including science itself. The misappropriation of the method of "pure" science to the study of social science is what Hayek (1952, p. 92) calls scientism-which, he warned, is "the characteristic outlook of the engineer, whose conceptions of "efficiency" constitute one of the most powerful forces through which this attitude has affected current views on social problems." In other words, scratch an engineer and you will find a central planner. Hayek regards this "engineering mindset" as dangerous because: "So far as the solution of his engineering problem is concerned, he [the engineer] is not taking part in a social process in which others may take independent decisions, but lives in a separate world of his own. His technique, in other words, refers to typical situations defined in terms of objective facts, not to the problem of how to find out what resources are available or what is the relative importance of different needs. He has been trained in objective possibilities, irrespective of the particular conditions of time and place, in the knowledge of those properties of things which remain the same everywhere and at all times and which they possess irrespective of a particular human situation (Hayek, 1952, pp. 168-169)" [...] [i]f Hayek's critique is to be taken seriously, the plurality of social constructs-embraced by champions of a 'new alliance' between natural and human sciences-poses a major impediment to that unification of knowledge they ardently seek. What I am suggesting is that the integration of natural and human sciences is more elusive than what is suggested by high-minded prose about ‘unification'» (Hébert, 2021, pp. 612-613). 
In light of this, Hébert argues that the economics-engineering alliance could be the Trojan horse with which the "engineering mentality" enters the walls of economics, permeating it with a constructivist logic that leads to social planning, i.e., an approach that claims to build a new society as engineers plan to build a bridge. ${ }^{5}$ Additionally, the ambiguous frameworks of interdisciplinary, transdisciplinarity, and so on, would help Ulysses's strategy, by going beyond Stuart Mill's dictum that «a person is not likely to be a good economist who is nothing else» (Mill, 1865, p. 77). Perhaps we will eventually see the substitution of economists and other social scientists with engineers and planners, in the name of the constructivism doctrine, which Hayek identifies politically as being socialist central planning (Hayek, 1967, p. 85). In fact, Hébert concluded his note, with the warning:

«[t]he inherent danger in a Prigogine alliance between economics and engineering is that what starts as an alliance could easily devolve into a merger, in which one field dominates another» (Hébert, 2021, p. 614).

Although along a different line of thought, Fforde (2021) also underlines the inappropriateness and danger of an engineering mentality in economics. The first impression I had while reading Adam Fforde's essay was that of finding myself faced with an ultra-skepticism like the one Isabelle Stengers expressed to me via email: «the pseudo-science called economics is unable to enter into any alliance, whatsoever» (stress added). Fforde is not inclined to think of economics as a social science with predictive power. Rather, he believes that economists in theorizing are sensitive to other criteria:

«I note in passing two prestigious economists (Friedman, 1953; Stigler, 1947) who assert that scientific method requires generation of theory with predictive power. From this it follows that economics is not a science (Fforde, 2021, p. 592) [...] Economics, it is obvious, does not have a practice that requires theories to be tested by their predictive power (Fforde, 2021, p. 592) [...] Mainstream economists, with their experience that model choice is not done by assessing predictive power, but by 'what the Prince likes', have powerful investments in certain forms of modelling» (Fforde, 2021, p. 594).

Taking this point of view on economics, he observes that the epistemological distance between it and engineering is too much to believe that a collaboration will ever work, even for the opportunistic reasons of academics and professionals. To sum Fforde's volcanic narrative, he states that engineers are happy if the bridge is standing and if it can be built at a given cost and within the shortest possible time, estimated through several alternative models.

«Engineering cannot be said to be about, in essence, 'fundamental laws'» (Fforde, 2021, p. 592). Engineers expand knowledge through practice, trial

\footnotetext{
${ }^{5}$ I also received a similar comment from Bruce Caldwell.
} 
and error in the evolution of design, which gives them solid predictive power. On the other hand, economists are almost entirely uninterested in it: «[f]or example, whilst standard theory states that if there is joint production or own consumption and so constrained optimisation cannot show how markets work, and therefore fulfill economics' ideological responsibilities, what happens if engineers happily deploy their mathematical skills to show that, yes markets won't work, but we can do this instead? What if the this implies a rejection of behaviourism, a push to endogenise model choice by, in effect, asking those modelled what they think? This, of course, rejects the underlying instrumental rationality hypothesis. [...] In other words, the assumption is that understanding humans means treating them like non-sentient machines: their subjectivity does not matter. This may not work, in the sense of designing and building something suitable» (Fforde, 2021, p. 594).

Thus, the mentality associated with economic pseudo-science conflicts with the engineering mentality, so that the two disciplines cannot easily work together.

In my opinion, both authors alert us to some of the real dangers of assuming a pure science mindset in the field of social science, but: (1) they attribute what is immanent in economics to the relationship with engineering; and (2) they reveal some confusion and perhaps misunderstanding about modern engineering and its evolution.

Concerning the first point, Hébert, referring to Hayek, points out the inadequacy and perniciousness of the assumption of scientism in the field of economics as a social science. Pure scientists stay in their ivory towers, without being part of the social process, but believe they can de-novo design and implement a better society. It is easy to reply with what the Gospel according to Saint John states- "let he who is without sin cast the first stone". Indeed, the mainstream of economic science has always defended its purity as strenuously as that of the woman in the biblical Song of Solomon. ${ }^{6}$ According to Robert Skidelsky, the author of the three-volume, awardwinning biography of John Maynard Keynes, «most academic disciplines have become highly specialized since Mill's day [...] But no branch of human inquiry has cut itself off from the whole-and from the other social sciences-more than economics [...] Economists claim to make precise what is vague, and are convinced that economics is superior to all other disciplines [...] and view economic problems as essentially mathematical problems. The efficient state of the economy, general equilibrium, is a solution to a system of simultaneous equations. Deviations from equilibrium are 'frictions', mere 'bumps in the road'; barring them, outcomes are predetermined and optimal. Unfortunately, the frictions that disrupt the machine's smooth operation are human beings [...] Today's professional economists [...] have studied almost nothing but economics. They don't even read the classics of their own discipline. Economic history comes, if at all, from data sets. Philosophy, which could teach them about the limits of the economic method, is a closed book» (Skidelsky, 2016, pp. 1-3).

\footnotetext{
${ }^{6}$ From which the image of the ivory tower originates.
} 
I believe that this state-of-the-art cannot be attributed to the penetration of engineering into the economic sphere, but rather to the autonomous emulation of the pure science epistemology by economists.

As Hébert notes, I did not refer to Hayek's critique of social rationalism and the engineering mentality in my article. However, agreeing with the perniciousness of its diffusion in the economic field, I discussed both the limits of the "economist as an engineer" paradigm, epistemologically design-oriented, and the dire consequences of a brotherhood between AI scientists/engineers and mainstream economists in the name of perfect neoclassical rationality and progress toward creating the mythical perfectly rational agent, i.e., the machina economica. In fact, the economic theory has been extremely reluctant to accept the implications of the new complexity, being somewhat inclined to associate sophisticated mathematical modeling with a reductionist approach, i.e., borrowing «some promising concepts and tools without changing their foundations and ideological commitments» (Mariotti, 2021, p. 565). I confirm my conviction that in our present times, this is the very engineering mentality that we should fight against, both at a research level, and at all teaching levels.

Secondly, both Fforde and Hébert seem to have a notion of engineering and its variety based on tradition, i.e. engineers who, regardless of the social context in which they are embedded, design machineries, plants, and infrastructures that respond to social needs, but which are offered cast in stone to a society that just has to adapt to them. ${ }^{7}$ But this is no longer the case. The memory and the analysis of the figure of Frederick Taylor, engineer and founder of scientific management, proposed in Adelstein (2021) would be enough to remove any doubt about the existence of a variety of engineers with their fingers in the pie of social processes. Generalizing, García-Díaz (2021) refers to academics and professionals who consider systems as human activity systems - industrial and systems engineers-and I would add management engineers, as well as environmental, energy and sustainability engineers (Mariotti, 2021; see also Sect. 7). This evolution has stimulated an important debate in the field of engineering philosophy aimed at understanding the profound changes that have been induced in its epistemology, where, to the traditional dimensions related to the application of natural and exact sciences, to design and the art of getting things done, the social dimension is added, according to which engineers are also seen as social experts, thanks to their ability to navigate social science, and to recognize the eminently social nature of the world they act upon (Figueiredo, 2008; Hynes \& Swenson, 2013; Kant \& Kerr, 2019).

\footnotetext{
7 Hayek's critique had the French econo-engineers of the nineteenth century, condemned as responsible for the penetration of the engineering mentality into the economy, as its reference. But Hébert himself had doubts about lumping them in a blanket condemnation (Hébert, 2001).
} 


\section{Opportunities and risks for the advancement of knowledge}

We can sum up our main arguments as follows. Mutual interactions between the "knowing" and the "willing" are essential for advances in both the field of economics and that of engineering. Generally speaking, isolation between pure science, experimental science and art (e.g., engineering and applied economics) has serious effects on the advancement of knowledge, favoring self-referentiality, epistemological hubris, and a lack of realistic assumptions.

As far as the economic-engineering nexus is concerned, there has been a reduction in epistemological divergences and fewer tensions between the two disciplines, at least in the field of applied economics and the socially-sensitive branches of engineering. Inappropriate mindsets are present in both disciplines, but they do not seem to be significantly attributable to the bad influence of one discipline on the other.

As we will see later on (Sect. 6), this rapprochement reflects a more general trend of cross-fertilization between disciplines and creates the conditions necessary to cross disciplinary boundaries and build bridges between the different fields of human knowledge. In the next Section, I will re-discuss the role of AI and complexity as factors that push in this direction.

Opportunities are always associated with risks. Hébert (2021) fears that a convergence, if encouraged and guided by institutional factors that promote closer relationships between the two disciplines, could have harmful effects, by transforming an alliance into a merger, in which one field dominates another. A cautionary tale is also expressed by Adelstein (2021), with reference to the historical parabola of Frederick Taylor's scientific management. In a nutshell, Adelstein considers "Taylorism" as transdisciplinary economics and engineering avant la lettre, as a result of Taylor's ideal aimed at proposing an objective science of work, for the benefit of workers as well as owners. He explains that:

«[Taylor] insisted, owners must do their part and share the profits created by the new methods fairly with workers; otherwise, the unity of interest and resolution of the eternal conflict of the workplace that were not just the promise but the very problem scientific management had been invented to solve could not be achieved. Taylor had tried to infuse his transdisciplinary enterprise with his own normative vision of the problems it would solve and what the best solutions might look like» (Adelstein, 2021, p. 578).

However, after his death in 1914, under the dominance of the capitalistic regime, the fate of Taylor's science was reduced to a purely profit-oriented version of engineering:

«[i]n this way, the normative direction Taylor had attempted to impose on his system was diverted, perhaps inevitably, to the maximization of profits for owners, and his transdiscipline reduced, as Sergio Mariotti suggests, to economics for engineering, a tool for corporate profit-making» (Adelstein, 2021, pp. 578-579). 
In other words, he warns us that, once economics become engineering, it must take on a purpose, a problem to solve or an objective to be achieved. So, given the historical contingencies, "management science" becomes economic engineering, intended to help firms earn more profit.

These risks should not be underestimated. Since the goals toward which powerful disciplines, such as management and engineering, are likely to be directed in our late capitalism/authoritarian world, I share the fear of such an outcome with Adelstein. However, I think this is a key problem that should be ascribed to all scientific disciplines in their positive (the "is"), normative (the "ought to be") and art (the "how") dimensions. Scientific advances do not take place in a vacuum, and are instead influenced by the institutional settings (a là Douglas North) in which scientists and research activities are embedded, which transmit ethics, values, beliefs, norms and rules of the game to them. As the advancement of knowledge increasingly benefits from the interactions between all the three disciplinary components, the insurance against associated social risks is not seclusion in the ivory tower, but participation (whatever this means: complicity, resistance, opposition or political action). Of course, this implies judgment. What I fear is not a new transdisciplinary alliance between economics and engineering in the name of knowledge, but as I argued in Mariotti (2021), the de-facto alliance, already achieved, between dogmatic economists and smart but incurious engineers, both super-true believers in homo economicus and now machina economica. In light of this, a crucial question remains to identify a good "governance" of the economics-engineering nexus to tip the balance in favor of opportunities and not risks (see Sect. 6).

\section{Technology and complexity call for bridging the gulf}

In Mariotti (2021), I identified AI and complexity as key factors, among others, that push toward bridging the gulf between economics and engineering, and toward effectively addressing the new socio-economic challenges. Some reflections and clarifications are presented hereafter on the basis of the critical comments received, and in particular those of Fforde (2021).

\subsection{Artificial intelligence}

In my paper, I generally used the term AI in a broad sense, according to which its epistemological content includes problems and ways of solving them that are characteristic of knowledge engineering, exploring them through the representation and computer manipulation of knowledge, reintegrating and generalizing them with the help of the computer, the related software, and machine learning. However, whatever definition of AI technology is given, it is a highly pervasive and integral component of our daily lives and of the business model of many organizations, as well as a key strategic element in the plans of many sectors of business, medicine and governments on a global scale (Dwivedi et al., 2021). 
Looking at the furthest-reaching implications of the AI cluster, scholars have proposed different, sometimes opposite, views of the transformation of capitalism (or its overcoming). Some have underlined the authoritarian potential of AI, coining various terms that emphasize the dangers to the freedom of individuals due to the concentration of data and knowledge in the hands of a few economic organizations and/or institutions: platform capitalism (Srnicek, 2017), surveillance capitalism (Zuboff, 2019), neuro capitalism (Helbing \& Hausladen, 2022), inhuman capitalism (Dyer-Witheford et al., 2019). Other scholars proposed that AI paves the way for a society of abundance, free goods and almost zero marginal reproduction costs, in many respects beyond capitalism: post-capitalism (Mason, 2015), digital socialism (Morozov, 2019), fully automated luxury communism (Bastani, 2019), are but some of the evocative terms used to represent this (r)evolution.

This literature should be taken with a grain of salt. Futurism can be a fruitless effort if it does not take into account that the future reality can take a multitude of different paths, depending on the past and open to the present action of humans. However, being doomed by reality to live forever with uncertainty, it is imperative for scholars to try to link technological forecasting with social and economic change, as transformative applications and social impacts of AI are expected in the near and intermediate future.

For these reasons, I do not agree with the perspective proposed by Fforde (2021), who suggests approaching AI as humans approached dogs in the past. He states:

«[n]obody, clearly, could have learnt how to trust an autonomous carnivore to play safely with their young daughter by sitting down to design 'it'; rather, they would have kept a close eye on them and been ready to kill it if it seemed necessary. And an AI can always be turned off. And, as something 'with teeth' in an important relationship with humans ... humans will either kill it, or learn to trust it, or die off before that can happen» (Fforde, 2021, pp. 598-599).

First, the metaphor seems to me inadequate to represent the relationship of humans with AI. In the example of algorithmic collusion that I proposed to elucidate the need for close collaboration between economists, engineers, and jurists to face AI challenges (Mariotti, 2021), it is true that it is humans (businessmen) who sit down to design their super-intelligent "algorithmic companion dog", and it is humans (antitrust authorities) who must protect society from the harm of collusion. This is a question between individuals of the same species and not between different species. Second, Fforde proposes approaching AI through observation and experiential learning. I believe he underestimates the pervasiveness and network effects of AI, which are going to create strong irreversibility and path dependency (David, 2001). Think of plastics, an innovation that is immeasurably less irreversible than AI and which is seriously polluting the environment. After its pervasive diffusion, is it easy to "kill" plastics? In reality, humans are still struggling to find remedies to the pollution it is causing. And since the future is open to human action, I prefer to try to foresee and prevent death rather than simply observe and risk it.

An AI scientist, Virginia Dignum (2019, p. 18; stress added) stated: «[a]ll technological change has traditionally been accompanied by fundamental societal changes. We are now at the brink of yet another one. It is up to us to make this a change for 
the better, for all of humankind and for the environment. This challenge is too large and too important to be left to engineers alone. All fields of knowledge from humanities and social science to art and design are needed to better build, understand and use AI». Curiously enough, although engineers seem to be concerned about the vast impact of AI and demand multidisciplinarity, according to Fforde, economists and other social scientists could limit themselves to a "wait and see" perspective. Indeed, what is needed is not futurism, or simple observation, but studies that integrate both the technical characteristics of AI systems and the social, economic, industrial and institutional context in which they are deployed.

\subsection{Complexity}

Fforde (2021) notes that I neither defined the meaning of complexity exactly, nor stated whether I referred to reality or to the model:

«[w]hether it is plausible to judge that society is becoming more-or lesscomplex depends on many factors, but there is a distinction between such judgements and the arguments made to support them: the extent to which models should be complex or not» (Fforde, 2021, p. 592).

Taking the example of the motion of the pendulum, he observes that the reality of the pendulum is only one, but that it can be modeled in a "simple" or "complex" way, according to the approximation required for our interpretation of reality. In light of this:

«[c]omplexity is then better seen as a perhaps characteristic of models, not reality. From this perspective, it is understandable but probably wrong to see that the failure of economists' models to secure predictive power can be explained as an "admission that agents are heterogeneous, rationality bounded and not perfectly informed has paved the way to a new age in economics, the "complexity era"' (Mariotti, 2021). In some sense, they always were. The bob of a pendulum is never, really, such that its centre of gravity is at its geometric centre: but it can work to assume that it is (or not, depending). It is obvious that a priori arguments about the extent to which this is the case, or not, reflect deep aspects of methodology: model choice was, and remains, determined by various factors, but predictive power is not one of them. If it were, the point would be about the degree of heterogeneity (etc.) related to what the model is meant to do when it predicts. A priori, humans can be said to be simple, complex, or somewhere in between; with a predictive criterion, and something to predict, an a priori answer is silly» (Fforde, 2021, p. 593-594).

To better explain my argument, I refer to Simon's approach to complexity. In his essay "Science seeks parsimony, not simplicity: Searching for pattern in phenomena," Simon (1967, p. 7) provided the following statement: «[t]he primordial acts of science are to observe phenomena, to seek patterns (redundancy) in them, and to 
redescribe them in terms of the discovered patterns, thereby removing redundancy. The simplicity that is sought and found beautiful is the simplicity of parsimony, which rests, in turn, on the exploitation of redundancy. We do not seek the absolutely simplest law but the law that is simplest in relation to the range of phenomena it explains, that is most parsimonious». ${ }^{8}$ Simon gave the definition of parsimony as the «relation between two strings: one representing a data set, the other representing a formula for that set. In general, we will be interested in data sets represented as sequences of raw observations, before they have been recoded to take advantage of any redundancy they may possess. The function of formulas is to exploit such redundancy when it can be discovered» (Simon, 1967, p. 5) [...] «[s]pecifically, parsimony is the ratio of the complexity of the data set to the complexity of the formula. To the extent to which a data set can be represented parsimoniously, we say that it is patterned, and we call the representing formula a pattern... [c]onsider two data sets, the second of which includes the first, and is thereby the more complex. Suppose that the same formula describes both sets. Then the parsimony of the relation of the formula with the larger data set is greater than the parsimony of its relation with the smaller set. Similarly, if two formulae describe the same data set, the parsimony of the relation with the simpler formula is greater than the parsimony of the relation with the more complex» (Simon, 1967, p. 6).

Accordingly, what I mean by "increasing complexity" is that to model contemporary reality, whatever the scope is (predictive or not), we are requested to be more redundant, i.e., in general, the most parsimonious scientific laws describing economic phenomena in present days are less parsimonious that in the past. As I tried to explain and exemplify, AI is one of the main drivers of this needed "diseconomy". Relatedly, Silvano Cincotti contributes to deepening the theme of complexity and its implications on scientific theorizing, concluding that:

«[i]n the framework of complexity, the scientific question moves from neoclassical problems on uniqueness and stability of the equilibrium in the economic systems to the theoretical determination of the conditions for self-referential situations characterized by the self-fulfilling prophecy of the economy. Simultaneously, the economic agents move from perfectly rational agents able to forecast the future without systematic errors to badly-informed boundedrational ones that create their future» (Cincotti, 2021, p. 586).

Finally, since the protagonists in the challenge of complexity are technological hardware and software systems resulting from the progress of computer science and an increasingly refined and scientificated engineering design (Simon's old, but very topical thesis), the need for a reconsideration of the relationship between economics and engineering emerges spontaneously in society and not from the conviction and imposition of some social planners. It is not a self-fulfilling operation, given the inertia and impediments due to the epistemological divergences commonly highlighted, but it instead requires a conscious search for «an alliance that brings

\footnotetext{
8 In doing so, Simon applies Occam's razor principle: "frustra fit per plura quod potest fieri per pauciora" (it is futile to do with more things that which can be done with fewer).
} 
these two disciplines separated over time - the hard science (exact, technological) versus the soft sciences (social, historical) — to a unitary and coherent vision of reality, which results from the integration of complementary economic and engineering constructs, the protection of plurality, and the determination to understand and tackle possible tensions» (Mariotti, 2021, p. 553; stress added).

\section{Disciplinary imperialism or alliance between disciplines?}

Swann (2021) aptly emphasizes that the likelihood of a meeting of disciplines being successful, in the sense of giving society what it needs, depends on governance, i.e., on the institutional forms that preside over the exchange of knowledge and the regulation of mutual disciplinary tasks. In the following, I discuss the alternatives of governance.

Historically, economics has created the conditions necessary to affirm the idea of putting disciplinary relations under the giant umbrella of "economics imperialism". Mäki (2009) reminded us how Robbins's (1935, p. 16) well-known definition of economics as «the science that studies human behavior as the relationship between poor ends and means that have alternative uses» gave rise to a powerful scope-expanding process of the discipline: «[a]fter all, the ends that men and women seek include not just bread and butter but also reputation, adventure, sex, status, eternal salvation, the meaning of life, and a good night's sleep» (Hirshleifer, 1985, 53). According to this concept, the scope of economics is not restricted to ordinary market phenomena: «[r]ational self-interested choice plays a role in many domains of life other than markets, for example in politics, warfare, mate selection, engineering design, and statistical decisions» (Hirshleifer, 1985; stress added).

In fact, this extended interpretation has paved the way toward economics imperialism, in a perspective that sees not only explanatory unification, but full consilience under the dominance of the economic theory (Mäki, 2009, p. 359). As Mäki argued, there is good and bad in economics expansionism. The "good thing" is that it «manifests a respectable philosophy of science» when searching for knowledge unification. The "bad thing" is that «economics imperialism suffers from unjustified radicalism and dogmatism that should deny it any support» (Mäki, 2009, p. 377), i.e. a self-importance that prevents serious attempts to meet the ontological, practical, and epistemological constraints whose respect makes a derivationally more unifying theory also a better theory. He concludes by arguing that economics imperialism should be distinguished from other types of interdisciplinary relations, while defending himself against the economic hubris on which economics imperialism is based, but without renouncing the yearning for unification.

Indeed, associated with economics imperialism, a position of social superiority of economists has emerged, which has bred self-confidence, allowed the discipline to maintain its epistemological insularity over time and fueled an inclination toward a sense of entitlement. Fourcade et al. (2015), for example, cited a survey conducted in the United States in 2006 which showed that mainstream economists were the only social scientists who opposed interdisciplinarity to a great extent: $57.3 \%$ of 
American economics professors disagreed with the statement that "in general, interdisciplinary knowledge is better than knowledge obtained by a single discipline" while, on average, $20.8 \%$ of other social scientists did so (professors in finance, history, political science, psychology, sociology).

In contrast, and quite ironically, in more recent times, we have witnessed an increasing assimilation by economics of other social sciences, with the incorporation of knowledge from psychology, sociology, neuroscience, biology, anthropology, etc. (Cedrini \& Fontana, 2018; Colander et al., 2011; Davis, 2006), as well as from engineering (Duarte \& Giraud, 2020). The most relevant case is perhaps that of behavioral economics, which has begun to question the mainstream (Angner, 2019). More generally, after economics had exported its view of rationality to other social sciences, new approaches have emerged within economics that import insights from other sciences, thus giving rise to a process that has been called "reverse imperialism" (Crespo, 2017; Davis, 2006).

Imperialism and reverse imperialism are criticized for envisioning an epistemological domain that would constrain and stifle the development of the interpretative and creative capacities of the disciplines. However, both reflect the aspiration of sciences toward unification. Mäki (2009, p. 357) noted: «[w]hatever the formulation, unification is widely celebrated as a major goal and achievement of the best of science.... There is little doubt that large segments of the economics profession share the view that unification is a major virtue of theorizing».

In contrasting pluralism to imperialism, Davis (2016) conducted an insightful discussion on how not to throw the baby out with the bathwater. He referred to the key concepts of complexity economics. According to which «[a]gents" "actions and strategies constantly evolve" and "structures constantly form and re-form" in a process of interaction at the "meso-layer" level that continually changes their relation to one another. If we take agents to be sciences and structures to be the relationships between sciences, then in a complex world the sciences and their relationships are constantly changing each other. Accordingly, sciences can only appear relatively autonomous in the short run. Their relatively independent identities, that is, are nominal in the sense of states of affairs that abstract [...] from the forces of influence that sciences have on one another. Perhaps one way of thinking of this is indeed in terms of investment in new domains, as in Chicago's economics imperialism idea. But that narrow, single channel surely under-estimates the variety of forms of interaction between sciences. At the very least, if there is economics imperialism, there are just as much other science imperialisms directed to economics' domain» (Davis, 2016, p. 92).

The antidote to this state-of-the-art is economic pluralism, which has flexible and evolutionary characteristics: «in an evolutionary world change is always occurring and somehow accompanies stability. Thus differences in how the sciences jointly and separately explain the world constantly emerge. Pluralism seen from this perspective is both a descriptive and normative view. That different approaches continually emerge is a fact about the nature of science [...] It also seems to be a fact about science that most people wish science should freely advance. From this, it seems entirely justified to recommend that science environments be open and pluralistic. Needless to say, the details of securing this goal are many and demanding 
in economics, because neoclassicism since the early reverse imperialism incursions from the 1980s has arguably become an increasingly defensive and yet aggressive approach. No support for pluralism seems likely to be found among the ranks of neoclassical economists. The risk is just too high to core principles. Thus as has only been too long clear, the defense of pluralism falls to heterodoxy» (Davis, 2016, p. 93).

In the field of economic-engineering relationships, I believe that the right form that pluralism should take on is an "alliance à la Prigogine" (not a merger, as feared by Hébert, 2021), according to which each discipline, with equal dignity, independence and mutual respect, agrees to be crossed and transformed by the other, in a context of coexistence and continuous emerging of new theoretical and practical approaches. My reference to Prigogine was perceived as suggestive and vague. However, Prigogine (2005) — to the best of my knowledge the only writing in which the Nobel laureate explicitly dealt with economics-clearly described the philosophical antecedents on which the alliance could be founded, underlining the convergence of physics and economics on the "laws of possibilities" in the name of the shared properties of irreversibility, instability, chaos and unpredictability of complex systems studied by both sciences: «[i]n all fields, whether physics, cosmology or economics, we come from a past of conflicting certitudes to a period of questioning, of new openings». This is «the historical time where physics meet economics [...] no longer is there a gap between the 'hard' science speaking of certitudes and the 'soft' science dealing with possibilities [...] the existence of value, and therefore also of economic value, is in line with our present description of the physical universe» (Prigogine, 2005, pp. 68-69).

In a subsequent paper, Davis (2019) argued that increasing specialization and a more niche-based economics may reduce the distinct identity of economics to a monolithic discipline by fostering more borrowing from other disciplines, thus favoring pluralism, as «what is more likely to promote pluralism is the argument that any discipline depends on sustaining its internal diversity - the perspective of the discipline as a whole-and the idea that diversity is intrinsic to entire systems» (Davis, 2019, p. 289). Davis outlined the reasons for such increasing specialization and fragmentation, starting from Smith's division of labor view, and Kuhn's thinking on the importance of specialization, and arriving at Arthur's theory of technological change as determinants of specialization in science, and at the effects of space, culture, and internationalization.

What I would like to underline is the close relationship of this vision with the one proposed in Swann's contribution (2021), albeit hidden by a veil of pessimism:

«a growing number of disciplines are closer to a federation of semi-autonomous sub-disciplines [...] Swann (2019, Ch. 12) surveyed some of the literature on this, and found that many more disciplines are now recognised as federations, including: medicine, physics, chemistry, biology, neuroscience, cognitive sciences/psychology, computer science/computing, business studies, materials science and engineering» (Swann, 2021, pp. 623-624).

As regard to economics, Swann's thinking is that his specialistic area-the economics of innovation-is a semi-autonomous hybrid discipline, at least in 
Europe. As he wrote in a mail to me, innovation economics draws on the work of scholars who have backgrounds in different disciplines, but whose principal interest is innovation, and who are willing to engage in something close to transdisciplinary work. I add that hybridization is favored in fields where the systemic complexity and relevance of the technologies require the search for a synthesis between the aggregate approach of the economist, who looks at technology as a black box (provided by "God and engineers", as in Joan Robinson's famous dictum), and the disaggregate modeling of the engineer who is required to match the economic values associated with more aggregate market variables. Past and present examples can be found in network industries: the foundation of energy economics in the last few years of the nineteenth century, in conjunction with the heavy intervention of many states in the production and distribution of energy (Evans \& Hunt, 2011); the creation of transport economics in the 1960s, thanks to the partnership of John Meyer and Martin Wohl (an engineer) and their seminal books wherein they used a combination of economics and engineering to understand mobility within cities (Meyer \& Wohl, 1965); the emergence of digital network economics, with its inextricable interweaving between the properties of ICT technologies and essential economic concepts, such as complementarity, compatibility, standards, externalities and switching costs (e.g., Shy, 2001).

However, Swann notes:

«[w]hile I would dearly like economics to be a federation, it is in reality a unitary state. Mainstream economics has sub-disciplines, but they are barely autonomous. The rules that govern what makes good research and good teaching are more or less the same in all sub-disciplines of economics» (Swann, 2021, p. 624).

Clearly, he refers to the dominant view of mainstream economics:

«Mariotti's proposal require economists to do things that economics departments do not value highly, and which mainstream economists are not in the habit of doing. If these unusual economists are to feel confident that they can do these activities without career risk, then they must work in an environment where the rules are different. That is, they must be located in a sufficiently autonomous sub-discipline» (Swann, 2021, p. 624).

I totally agree with him. As in medicine, economics should be a federation of semi-autonomous sub-disciplines open to the contribution of other disciplines and methodological pluralism. Alliances need autonomy and require the meeting of integral thinkers who are mindful and conscious of the need for plurality, that is, «scholars well rooted in their own discipline, but who are open to change their attitude, becoming less self-referential and not abusing disciplinary formalism» (Mariotti, 2021, p. 568). If Davis's analysis is correct, this is not only a normative wish (that ought to guide economists' research goals and the organization of research), but also a descriptive sense regarding the role that diversity, semi-autonomy, and cooperation is happening in the development of economics. 


\section{Alliance and transdisciplinarity re-discussed}

As outlined in the previous Section, the movement toward disciplinary intertwining appears a constant in the evolution of economics, as for other disciplines, but it has assumed forms of disciplinary domination that have been caused by the excess of the epistemological hubris of the different scientific castes. Therefore, it does not appear at all senseless to propose policies for the advancement of sciences that would be able to exploit the potential inherent to these processes, that is, freeing up resources through different modes of interaction. This is the meaning of the alliance I have proposed in the specific context of the relationship between economics and engineering, but which is open to other disciplines, respectful of singularities, and able to guarantee "equal dignity", in accordance with Adelstein's point:

«only economics and engineering, the recognition of social science and social engineering as distinct disciplines, each with its own role and epistemology, provides the independence and critical distance necessary for both economists and policymakers to step back and consider how scientific knowledge is being used, who is being controlled, and toward what end» (Adelstein, 2021, p. 576).

Interestingly, social scientists are also requesting that the boundaries of their disciplines should be pushed further by involving them in more interdisciplinary work. For instance, in the field of law, Calabresi (2016) forcefully called for a passage from an "economics of law" approach (where law is a subject of analysis) to an "economics and law" one in which the two disciplines enrich each other on a "parity basis". Analogously, in the field of organization science, Grandori (2021) observes that Williamsonian transaction cost economics «is not exactly an economics of organization; it is an economics and organization», and suggests the necessity for a wider, more inclusive, interdisciplinary science of economic organization. ${ }^{9}$

Alliance is figuratively like an "agreement picture" signed by the various disciplines, which implies flexibility and dynamic adaptability, but in which a convergent orientation to the "knowing" and/or the "willing" constitutes its cement. By using Su and Colander's metaphor of general contractor, in a "willing-oriented" alliance, this role is contingent on the specific project, i.e., it could be performed alternatively by an applied economist, a management engineer, a sociologist, a neuroscientist, etc. In other words, the governance of the alliance depends on the problem that has to be solved jointly, which makes the emergence and consolidation of epistemological and disciplinary hierarchies less likely.

Ultimately, it was the yearning for a prospect of unification of knowledge that inspired me when I wrote-with reference to Prigogine's belief to find a junction between natural and social science - that the mission of an economics-engineering alliance is «to restore a unified knowledge based on plurality, diversity and multiple perspective» (Mariotti, 2021, p. 566; stress added); where "restore" means to

\footnotetext{
9 It is worth noting they use the same prepositions - from "of" to "and" - that I used in my previous article.
} 
remedy the hyper-specialization that has characterized both economic science and applied economics in recent decades.

The alliance brought to mind the concept of transdisciplinarity. I am not a transdisciplinarian scholar. I have never used this concept or even the expression in any of my previous works. I arrived at transdisciplinarity inductively, using its constructs in a mainly evocative way. I was therefore not surprised by Hébert's remark that I was vague and inconclusive about it, and I agree with Adelstein's affirmation that my proposal of trandisciplinary integration is suggestive rather than substantive.

These criticisms lead me to confront the different theories and methodologies of transdisciplinary scholars in greater depth. According to McGregor (2015), who compared, for the first time in any detail, the two main approaches to transdisciplinarity, I follow the Zürich approach and not Nicolescu's methodology to create new knowledge. While Nicolescu worked out a unique definition of transdisciplinarity, grounded on metaphysics and quantum physics, and proposed a methodology axiomatic in ontology, logic and epistemology, the scholars who attended the 2000 Zürich International Transdisciplinary Conference (Klein et al., 2001) focused on how science and research can accommodate complexity, mainly through disciplines working together within the constraints placed on them by the context within which the knowledge should be applied. Furthermore, the Zürich approach borrowed a conceptualization on how knowledge is produced from Gibbons et al. (1994), the socalled "Mode 2", as an alternative to "Mode 1".

In Mode 1, knowledge is exclusively created within specialized disciplines, with problems shaped by the academic community, which is largely divorced from the world (the already mentioned "ivory tower syndrome"). Mode 2 looks at modern science as increasingly project-oriented, contextualized and thus confronted with structuring problems that change according to the situation. Therefore, it conceives the production of knowledge as emerging together with the evolving framework to address problems in the context of application, so that the found solutions are a genuine contribution to knowledge, whose creation is viewed as a cumulative process that goes beyond disciplinary maps. The production of knowledge in Mode 2 requires more transitory, flexible structures and flatter hierarchies than in Mode 1. The composition of the group dealing with the problem changes over time as the requirements evolve. The resulting knowledge is socially robust, accountable and reflective. Everyone should try to operate from the point of view of all the actors involved, which poses the challenge of sharing the values and preferences of the different members of the research team.

Mode 2, which has been revised in various ways in the literature (e.g., Nowotny et al., 2003), ${ }^{10}$ is actually very close to my thinking on how to face, "in the field", the complex problems posed by the interactions between business, society and AI, both going beyond interdisciplinarity, in which the disciplines, although interacting, remain on their own, and avoiding unrealistic "new sciences" from being achieved and even hypothesized. The discussion in Mariotti (2021) on algorithmic collusion

\footnotetext{
10 The emergence of literature aimed at closing the gap between the two modes of transdisciplinary research (e.g., Rigolot, 2020) is worth noting.
} 
and other social challenges posed by AI is illustrative. However, I must admit that the actions and strategies necessary to arrive at an effective implementation of Zürich school's transdisciplinarity are still lacking on my part. Fortunately, the contributions of García-Díaz (2021) and Cyrille Rigolot (2021), albeit in very different ways, put forward ideas and arguments on how to implement the "new alliance" in a context of transdisciplinarity.

In his valuable note, after proposing a fine-grained analysis of the epistemological differences between economics and engineering and also between the "traditional design" and "design as co-participation" of engineers, García-Díaz argues that systems engineering, on the one hand, and complexity economics, on the other, may serve as a bridge to bring the two disciplines close together and to favor their alliance, as:

«[m]any of the systems principles that are shared by systems engineers [...] are also shared by complexity and evolutionary economists [...] Arguably, complexity science and systems thinking are under the same roof of systems approaches as they share compatible ontological principles» (García-Díaz, 2021, p. 604).

On the engineering side, he refers to those engineers that study human activity systems. He mentions major associations that group such scholars together and, among them he mentions the International Council on Systems Engineering, which, in a revealing manner, declares its aim to be: «to develop and disseminate the transdisciplinary principles and practices that enable the realization of successful systems» (https://www.incose.org/about-incose; stress added).

On the economics side, he argues:

«[s]ystems approaches have had a closer relationship with systems engineering than with economics, and that is why I believe complexity economics may in part serve as a bridge nowadays [...] it is hard to find economists interested in the systems approaches», but "[a] diverse set of pressing societal challenges are right now necessitating a transdisciplinary focus, and thus are serving as meeting spaces for engineers and economists. These challenges relate to issues in ecological and environmental economics; post-carbon and post-growth futures; systemic risks; circular economies; urban sustainability; social protection and the Covid-19 pandemic effects on labor transformation; and many others» (García-Díaz, 2021, p. 606).

He adds that epistemological convergence, which favors a thorough understanding of pluralistic economics by systems engineers, is pushed by the accelerated scientification of engineering, which in turn is needed to deal with the fourth industrial revolution (AI-influenced). García-Díaz also argues - and I totally agree-that the economics-engineering alliance might materialize only along some directions, and outside the mainstream. However:

«[e]specially in European circles, the heterodoxy has gained a little more value, and policy discussions are willing to embrace pluralism» (García-Díaz, 2021, p. 606). 
Finally, Rigolot (2021) opens a wider window from the house of transdisciplinary scholars, to look at the alliances between disciplines. He gives methodological indications on the organization of a transdisciplinary university and outlines transdisciplinary initiatives in synergy with those of the economics-engineering alliance, which I neglected. Specifically, he draws attention to the research field of sustainability that:

«has been producing increasingly robust frameworks and tools to integrate different kinds of knowledge [...], to ensure or evaluate the practical implications of this integration on the ground [...] In my understanding, the research field of "ecological economics" is typically (at least partly) a significant effort toward a kind of transdisciplinary "alliance" between economy and ecology» (Rigolot, 2021, p. 617).

These contributions give some concreteness to the transdisciplinary perspective, thus helping to fill a gap in my previous discussion. However, the modalities of its effective implementation require much more research on the needed institutional changes, investments, and policies, also taking into account the warning of Hébert, i.e., to be aware that:

«the rise of populist governments and identity politics in both America and Europe makes resource allocation of the required magnitude a hard sell» (Hébert, 2021, p. 613).

\section{Conclusion}

These are some responses to the rich critiques presented by Adelstein, Cincotti, Fforde, García-Díaz, Hébert, Rigolot, and Swann. Before concluding, I would like to reiterate my indebtedness to the seven authors for what I have learned from their respective arguments. At the same time, I hope that the published contributions, as a whole, will stimulate a debate that too often takes place only in philosophy of science, epistemology, methodology and history journals. Given the relevance of the arguments and problems posed for an effective policy of scientific and technological progress, I hope that their discussion will become common practice and the patrimony of a wider set of scientific journals.

Acknowledgements I thank Luca Grilli and Riccardo Marzano whose comments and suggestions helped improve and clarify this manuscript.

\section{Declarations}

Conflict of interest The author states that there is no conflict of interest.

\section{References}

Adelstein, R. (2021). Economics not engineering. Journal of Industrial and Business Economics, 48(4), 573-579. https://doi.org/10.1007/s40812-021-00194-X 
Angner, E. (2019). We're all behavioral economists now. Journal of Economic Methodology, 26(3), 195207. https://doi.org/10.1080/1350178X.2019.1625210

Bastani, A. (2019). Fully automated luxury communism. Verso.

Blaug, M. (1992). The methodology of economics: Or, how economists explain. Cambridge University Press.

Calabresi, G. (2016). The future of law and economics: Essays in reform and recollection. Yale University Press.

Cedrini, M., \& Fontana, M. (2018). Just another niche in the wall? How specialization is changing the face of mainstream economics. Cambridge Journal of Economics, 42(2), 427-451. https://doi.org/ 10.1093/cje/bex003

Cincotti, S. (2021). Facing the complexity of the economy: An opportunity for the new alliance between economics and engineering. Journal of Industrial and Business Economics, 48(4), 581-588.

Colander, D., Holt, R., \& Rosser, J. B. (2011). The complexity era in economics. Review of Political Economy, 23(3), 357-369. https://doi.org/10.1080/09538259.2011.583820

Colander, D., \& Su, C.-H. (2015). Making sense of economists' positive-normative distinction. Journal of Economic Methodology, 22(2), 157-170. https://doi.org/10.1080/1350178X.2015.1024877

Crespo, R. F. (2017). Economics and other disciplines: Assessing new economic currents. Routledge.

David, P. A. (2001). Path dependence, its critics and the quest for "historical economics." In P. Garrouste \& S. Ioannides (Eds.), Evolution and path dependence in economic ideas: Past and present (pp. 15-40). Edward Elgar.

Davis, J. B. (2005). Robbins, textbooks, and the extreme value neutrality view. History of Political Economy, 37(2), 191-196. https://doi.org/10.1215/00182702-37-2-191

Davis, J. B. (2006). The turn in economics: Neoclassical dominance to mainstream pluralism. Journal of Institutional Economics, 2(1), 1-20. https://doi.org/10.1017/S1744137405000263

Davis, J. B. (2016). Economics imperialism versus multidisciplinarity. History of Economic Ideas, 24(3), 77-94. https://doi.org/10.19272/201606103004

Davis, J. B. (2019). Specialization, fragmentation, and pluralism in economics. The European Journal of the History of Economic Thought, 26(2), 271-293. https://doi.org/10.1080/09672567.2018.1555604

Dignum, V. (2019). AI is multidisciplinary. AI Matters, 5(4), 18-21. https://doi.org/10.1145/3375637. 3375644

Duarte, P. G., \& Giraud, Y. (Eds.) (2020). Economics and engineering: Institutions, practices, and cultures. History of Political Economy, 52(S1), 1-332.

Duflo, E. (2017). The economist as plumber. American Economic Review, 106(5), 1-26. https://doi.org/ 10.1257/AER.P20171153

Dwivedi, Y. K., Hughes, L., Ismagilova, E., et al. (2021). Artificial intelligence (AI): Multidisciplinary perspectives on emerging challenges, opportunities, and agenda for research, practice and policy. International Journal of Information Management, 57, 101994. https://doi.org/10.1016/j.ijinfomgt. 2019.08.002

Dyer-Witheford, N., Kjosen, A., \& Steinhoff, J. (2019). Inhuman power: Artificial intelligence and the future of capitalism. Pluto.

Evans, J., \& Hunt, L. C. (Eds.). (2011). International handbook on the economics of energy. Edward Elgar.

Fforde, A. (2021). Engineering, economics, Heidegger ... and Mariotti: A note. Journal of Industrial and Business Economics, 48(4), 589-600. https://doi.org/10.1007/s40812-021-00195-w

Figueiredo, A. D. (2008). Towards an epistemology of engineering. In: Proceedings of the Workshop on Philosophy \& Engineering (WPE 2008). Royal Engineering Academy.

Fourcade, M., Ollion, E., \& Algan, Y. (2015). The superiority of economists. Journal of Economic Perspectives, 29(1), 89-114. https://doi.org/10.1257/jep.29.1.89

Friedman, M. (1953). Essays in positive economics. University of Chicago Press.

García-Díaz, C. (2021). Design, systems approaches, and the engineering-economics nexus. Journal of Industrial and Business Economics, 48(4), 601-607. https://doi.org/10.1007/s40812-021-00199-6

Gibbons, M., Limoges, C., Nowotny, H., Schwartzman, S., Scott, P., \& Trow, M. (1994). The new production of knowledge. The dynamics of science and research in contemporary science. Sage.

Grandori, A. (2021). Pushing the boundaries of Williamson's 'science of economic organization': Knowledge and pluralism challenges. Society of Institutional and Organizational Economics Annual Conference, 24-26 June. 
Hands, D. W. (2012). The positive-normative dichotomy and economics. In U. Mäki (Ed.), Philosophy of economics, Vol. 13 of D. Gabbay, P. Thagard \& J. Woods (Eds.), Handbook of the Philosophy of Science (pp. 219-239). Elsevier.

Hayek, F. A. (1952). The counter-revolution of science: Studies on the abuse of reason. Free Press.

Hayek, F. A. (1967). Studies in philosophy, politics and economics. Simon and Schuster.

Hébert, R. F. (2001). Hayek and the French engineers. In T. Aimar, J. Birner, \& P. Garrouste (Eds.), F.A. Hayek as a political economist: Economic analysis and values (pp. 15-25). Routledge.

Hébert, R. F. (2021). Prospects for a Prigogine alliance between economics and engineering. Journal of Industrial and Business Economics, 48(4), 609-614. https://doi.org/10.1007/s40812-021-00198-7

Helbing, D., \& Hausladen, C. (2022). Socio-economic implications of the digital revolution. In P. Chen, W. Elsner, \& A. Pyka (Eds.), Handbook of complexity economics. Routledge.

Hirshleifer, J. (1985). The expanding domain of economics. American Economic Review, 75(6), 53-68. http://www.jstor.org/stable/1914329

Hynes, M., \& Swenson, J. (2013). The humanistic side of engineering: Considering social science and humanities dimensions of engineering in education and research. Journal of Pre-College Engineering Education Research, 3(2), 31-42. https://doi.org/10.7771/2157-9288.1070

Ivarola, L. (2018). A plea for realistic assumptions in economic modelling. Theoria: an International Journal for Theory, History and Foundations of Science, 33(3), 417-433. https://doi.org/10.1387/ theoria.18133

Kant, V., \& Kerr, E. (2019). Taking stock of engineering epistemology: Multidisciplinary perspectives. Philosophy \& Technology, 32(4), 685-726. https://doi.org/10.1007/s13347-018-0331-5

Keynes, J. N. (1890). The scope and method of political economy. MacMillan.

Klein, J. T., Grossenbacher-Mansuy, W., Häberli, R., Bill, A., Scholz, R., \& Welti, M. (Eds.). (2001). Transdisciplinarity: Joint problem solving among science, technology, and society. Birkhäuser.

Landry, J.-F., Dussault, J.-P., \& Mahey, P. (2013). A heuristic-based planner and improved controller for a two-layered approach for the game of billiards. IEEE Transactions on Computational Intelligence and Ai in Games, 5(4), 325-336. https://doi.org/10.1109/TCIAIG.2013.2284385

Leontief, W. (1971). Theoretical assumptions and nonobserved facts. American Economic Review, 61(1), 1-7. http://www.jstor.org/stable/1910537

Mäki, U. (2009). Economics imperialism: Concept and constraints. Philosophy of the Social Sciences, 39(3), 351-380. https://doi.org/10.1177/0048393108319023

Mariotti, S. (2021). Forging a new alliance between economics and engineering. Journal of Industrial and Business Economics, 48(4), 551-572. https://doi.org/10.1007/s40812-021-00187-w

Mason, P. (2015). Postcapitalism: A guide to our future. Allen Lane.

McGregor, S. L. T. (2015). The Nicolescuian and Zurich approaches to transdisciplinarity. Integral Leadership Review, 15(2), 6-16. http://integralleadershipreview.com/13135-616-the-nicolescuian-andzurich-approaches-to-transdisciplinarity/

Meyer, J. R., \& Wohl, M. (1965). The urban transportation problem. Harvard University Press.

Mill, J. S. (1865). Auguste Comte and positivism. Trabner.

Mirowski, P. (1990). Learning the meaning of a dollar: Conservation principles and the social theory of value in economic theory. Social Research: An International Quarterly 57(3), 689-717. https:// www.jstor.org/stable/40970609

Mongin, P. (2006). Value judgments and value neutrality in economics. Economica, 73(290), 257-286. https://doi.org/10.1111/j.1468-0335.2006.00501.x

Morozov, E. (2019). Digital socialism? The calculation debate in the age of big data. New Left Review, 116/117, 19-46.

Nierhoff, T., Leibrandt, K., Lorenz, T., \& Hirche, S. (2016). Robotic billiards: Understanding humans in order to counter them. IEEE Transactions on Cybernetics, 46(8), 1889-1899. https://doi.org/10. $1109 /$ tcyb.2015.2457404

Nowotny, H., Scott, P., \& Gibbons, M. (2003). 'Mode 2' revisited: The new production of knowledge. Minerva, 41(3), 179-194. https://doi.org/10.1023/A:1025505528250

Ostapiuk, A. (2020). The eclipse of value-free economics: The concept of multiple self versus homo economicus. Publishing House of Wroclaw University of Economics and Business.

Prigogine, I. (2005). The rediscovery of value and the opening of economics. In K. Dopfer (Ed.), The evolutionary foundations of economics (pp. 61-69). Cambridge University Press.

Rigolot, C. (2020). Quantum theory as a source of insights to close the gap between mode 1 and mode 2 transdisciplinarity: Potentialities, pitfalls and a possible way forward. Sustainability Science, 15(2), 663-669. https://doi.org/10.1007/s11625-019-00730-8 
Rigolot, C. (2021). Organizing and better understanding transdisciplinarity in the context of artificial intelligence expansion: A crucial role for the new alliance between economics and engineering. Journal of Industrial and Business Economics, 48(4), 615-620. https://doi.org/10.1007/ s40812-021-00196-9

Robbins, L. (1935). An essay on the nature and significance of economic science. Macmillan.

Schmidt, J. A. (2013). Engineering as Willing. In D. Michelfelder, N. McCarthy, \& D. Goldberg (Eds.), Philosophy and engineering: Reflections on practice, principles and process (pp. 103-111). Springer.

Shy, O. (2001). The economics of network industries. Cambridge University Press.

Simon, H. A. (1967). Science seeks parsimony, not simplicity: Searching for pattern in phenomena. Carnegie Mellon University, Complex Information Processing Working Paper 534. Reprinted: Simon, H. A. (2001). Science seeks parsimony, not simplicity: Searching for pattern in phenomena. In A. Zellner, H. A. Keuzenkamp, \& M. McAleer (Eds.), Simplicity, inference and modelling. Keeping it sophisticatedly simple. (pp. 32-72). Cambridge University Press.

Simon, H. A. (1995). Artificial intelligence: An empirical science. Artificial Intelligence, 77(1), 95-127. https://doi.org/10.1016/0004-3702(95)00039-H

Skidelsky, R. (2016). Economists versus the economy. Project Syndicate, December 23. https://memof in-media.s3.eu-west-3.amazonaws.com/uploads/library/pdf/Economists\%20versus\%20the\%20Eco nomy\%20by\%20Robert\%20Skidelsky\%20-\%20Project\%20Syndicate.pdf. Accessed 1 Oct 2021.

Stigler, G. J. (1947). The theory of price. Macmillan.

Srnicek, N. (2017). Platform capitalism. Polity Press.

Su, H.-C., \& Colander, D. (2021). The economist as scientist, engineer or plumber? Journal of the History of Economic Thought, 43(2), 297-312. https://doi.org/10.1017/S1053837220000231

Swann, G. M. P. (2019). Economics as anatomy: Radical innovation in empirical economics. Edward Elgar.

Swann, G. M. P. (2021). Alliances need autonomy. Journal of Industrial and Business Economics, 48(4), 621-626. https://doi.org/10.1007/s40812-021-00197-8

Zuboff, S. (2019). The age of surveillance capitalism: The fight for a human future at the new frontier of power. Profile Books.

Publisher's Note Springer Nature remains neutral with regard to jurisdictional claims in published maps and institutional affiliations. 